\title{
Real world evidence of calcifediol use and mortality rate of COVID-19 hospitalized in a large cohort of 16,401 Andalusian patients
}

Carlos Loucera $^{1,2}$, María Peña-Chilet ${ }^{1,2,3}$, Marina Esteban-Medina ${ }^{1,2}$, Dolores MuñoyerroMuñiz $^{4}$, Román Villegas ${ }^{4}$, Jose Lopez-Miranda ${ }^{5,6}$, Jesus Rodriguez-Baño ${ }^{2,7,8}$, Isaac Túnez $^{9,10,11,12}$, Roger Bouillon ${ }^{13}$, Joaquin Dopazo ${ }^{1,2,3,14, *}$, Jose Manuel Quesada Gomez ${ }^{10,15, *}$

1Clinical Bioinformatics Area. Fundación Progreso y Salud (FPS). CDCA, Hospital Virgen del Rocio. 41013. Sevilla. Spain;

2 Institute of Biomedicine of Seville (IBIS), Hospital Virgen del Rocio. 41013. Sevilla. Spain;

3 Bioinformatics in Rare Diseases (BiER). Centro de Investigación Biomédica en Red de Enfermedades Raras (CIBERER). FPS. Hospital Virgen del Rocio. 41013. Sevilla. Spain

4 Subdirección Técnica Asesora de Gestión de la Información. Servicio Andaluz de Salud. Sevilla, Spain

5 Internal Medicine Department, IMIBIC/Reina Sofia University Hospital/University of Cordoba, 14004, Cordoba, Spain.

6 CIBER Fisiopatologia Obesidad y Nutricion (CIBEROBN), Instituto de Salud Carlos III, 28029, Madrid, Spain.

7 Unidad Clínica de Enfermedades Infecciosas, Microbiología y Medicina Preventiva, Hospital Universitario Virgen Macarena, Sevilla, Spain

8 Departamento de Medicina, Universidad de Sevilla, Spain

9 G. Técnico de Expertos de Andalucía para Estudios de Suplementos e Intervención Nutricional Frente a Covid-19, SGIDIS. Consejería de Salud y Familias. Junta de Andalucia, Sevilla, Spain

10 Instituto Maimónides de Investigacion Biomédica de Córdoba (IMIBIC), 14004, Córdoba, Spain

11 Departamento de Bioquimica y Biología Molecular, Facultad de Medicina y Enfermería, Universidad de Córdoba. Córdoba, Spain

12 Secretaria General de Investigación, Desarrollo e Innovación en Salud, Consejería de Salud y Familias de la Junta de Andalucía.

13 Clinical and Experimental Endocrinology, Department of Chronic Diseases and Metabolism, KULeuven, Herestraat, 3000 Leuven, Belgium

14 FPS/ELIXIR-ES, Fundación Progreso y Salud (FPS). CDCA, Hospital Virgen del Rocio. 41013. Sevilla. Spain

15 CIBER de Fragilidad y Envejecimiento Saludable (CIBERFES). Hospital Universitario Reina Sofía. Universidad de Córdoba. Menéndez Pidal s/n, 14004, Córdoba, Spain.

* Corresponding authors 


\begin{abstract}
Background: COVID-19 is a major worldwide health problem because of acute respiratory distress syndrome, and mortality. Several lines of evidence have suggested a relationship between the vitamin D endocrine system and severity of COVID-19.
\end{abstract}

Methods: We present a retrospective survival study that includes all Andalusian patients hospitalized between January and November 2020 because of COVID-19 infection. Based on a central registry of electronic health records (the Andalusian Population Health Database, BPS), prescription of vitamin D or its metabolites within 15-30 days before hospitalization were recorded. The effect of treatment with vitamin D metabolites for other indication previous to the hospitalization was studied with respect to patient survival by means of Kaplan-Meyer survival curves and Log Hazard Ratios, using a propensity score to compensate the disbalance of compared classes and the confounding factors. The availability of detailed patient data in the BPS allowed to obtain Real-World Evidence (RWE) of the effects of prior use of vitamin D or its metabolites on the mortality due to COVID-19 infection.

Findings: A retrospective cohort of 16.401patients was extracted from the BPS, which includes all the patients hospitalized with COVID-19 diagnosis between January and November 2020 in Andalusia, one of the largest regions in Europe with the size of an average median country. A total of 358 patients were found with cholecalciferol, and 193 with calcifediol, prescriptions 15 days before hospitalization. For a period extended to 30 days before hospitalization, the numbers increase to 416 and 210 and, respectively. Kaplan-Meyer survival curves and hazard ratios support an association between consumption of these metabolites and patient survival. Such association was stronger in calcifediol (Log Hazard Ratio, LHR $=-1.27 \pm 0.32$ ) than in cholecalciferol $(\mathrm{LHR}=-0.56 \pm 0.15$ ), when prescribed 15 days before hospitalization This effect decreases when a larger 30 days period is considered (calcifediol LHR $=-1.01 \pm 0.27$ and cholecalciferol $\mathrm{LHR}=-0.27 \pm 0.12$ ), suggesting that the closer was the treatment to the hospitalization the stronger the association.

Conclusions: A significant reduction in mortality in patients hospitalized with COVID-19 is associated with the prescription of vitamin D, especially calcifediol, within 15-30 days prior to hospitalization.

\title{
Introduction
}

Vitamin D deficiency has been associated with a large number of diseases including immune disorders and infections. The causal role of vitamin D for rickets and osteomalacia is well demonstrated and its role in aggravating osteoporosis is well accepted [1]. Vitamin D3 (cholecalciferol), the threshold nutrient of the vitamin D endocrine system (VDES), is acquired by cutaneous synthesis under the influence of UV-B light and in minimal amounts from the diet. It is transported, like other VDES metabolites, by vitamin D-binding protein (DBP) (GC), in the liver, mainly through the action of 25 hydroxylase ( $C Y P 2 R 1$ and others), where it is converted to $25 \mathrm{OH}$ vitamin $\mathrm{D}$ (25OHD) or calcifediol, biomarker of nutritional status and pre-hormone of the VDES. The 25OHD is substrate for the synthesis of $1,25(\mathrm{OH}) 2 \mathrm{D}$ or calcitriol through the action of $1 \alpha$ hydroxylase $(C Y P 2721 B)$ in the kidney, for its endocrine actions, and in multiple 
cells of the body for its auto/paracrine action. The system hormone calcitriol binds with high affinity to its nuclear receptor, the vitamin $\mathrm{D}$ receptor $(V D R)$, regulating transcription of a large number $(\sim 3 \%)$ of genes, with a broad spectrum of functional activities[1]. However, its extraskeletal effects are more disputed. Several Mendelian Randomization studies demonstrated that genetically low serum 25-hydroxyvitamin D (25OHD) concentrations increase the risk of multiple sclerosis [2] and a meta-analysis found a reduced incidence of upper respiratory infections when supplements of vitamin D are given to relatively vitamin D deficient subjects [3]. There are now multiple association studies linking a poor vitamin D status with increased risk [4-7] or severity of COVID-19 infections [7-10] and also meta-analyses [11-13].

A recent UK study by NICE, however, concluded that there is insufficient evidence to recommend vitamin D supplementation solely for the purpose of prevention of COVID-19 (complications) but recommends the UK guidelines to prevent vitamin D deficiency in general. The NICE experts agreed that a poor vitamin D status was associated with more severe outcomes from COVID-19 but without proof of causality, especially because the risk factors for severe COVID-19 outcomes are also risk factors for low vitamin D status [14]. Similarly, a resolution of the US congress recommended correction of vitamin D deficiency in the general population as part of a global strategy to reduce the burden of COVID-19 [15]. Moreover, a recent study on systematic drug repurposing for COVID-19 based on machine learning has found that, among others, the VDR protein could have a protector effect over pathways affected by the SARS-CoV-2 infection [16], suggesting a potential protector role for VDES metabolites such as cholecalciferol, calcifediol or calcitriol. This study used mechanistic models [17] of the COVID-19 disease map [18] to find relevant interactions between proteins (already targets of drugs with other indications) and the pathways affected by COVID-19 disease infection either directly or downstream, collectively known as the COVID-19 disease map [18], thus providing mechanistic evidences of the protective effect of VDES metabolites in COVID-19.

Although randomized clinical trials remain the gold standard to proof efficacy and safety of whatever interventions [19], other types of studies may be faster and more efficient to provide clinical guidelines, especially when lifesaving procedures are needed in an emergency situation such as the present COVID-19 pandemic. Thus, the increasing availability of digital health data, together with the raising costs and known limitations of traditional trials, has fostered the interest in the use of real-world data (RWD) [20], defined as patient's data on their health status and on health care received, collected from their electronic health records (EHR) [20, 21]. RWD can be analyzed to generate real word evidence (RWE) [22]. Actually, RWE provide a better image of the actual clinical environments in which medical interventions are carried out when compared to conventional randomized clinical trials, given that RWD includes 
detailed data on patient demographics, comorbidities, adherence, and simultaneous treatments $[23,24]$.

Since 2001, the Andalusian Public Health System is thoroughly storing all the EHRs data of Andalusian patients in the Population Health Base (BPS) [25]. This makes of BPS one of the largest repositories of highly detailed clinical data in the world (with over 13 million of comprehensive registries) [25]. BPS constitutes a unique and privileged environment to carry out large-scale RWE studies, with especial attention payed to the evaluation of impact in personal data protection [26].

Here we used RWD from BPS to obtain RWE of the effectiveness of the treatment of cholecalciferol, calcifediol or calcitriol VDES metabolites with nutrient, pre-hormone or hormone activity respectively previously administered by other health objectives, on mortality rate among patients hospitalized for COVID-19.

\section{Material and Methods}

\section{Design and patient selection}

This study aimed to study a retrospective cohort including all the Andalusian patients with COVID-19 diagnosis that were hospitalized. Following the inclusion criteria of having a COVID-19 diagnosis (by PCR or antigens test) and an overlapping hospitalization during the period January to November.

The Ethics Committee for the Coordination of Biomedical Research in Andalusia approved the study "Retrospective analysis of all COVID-19 patients in the entire Andalusian community and generation of a prognostic predictor that can be applied preventively in possible future outbreaks" $\left(29^{\text {th }}\right.$ September, 2020, Acta 09/20) and waived informed consent for the secondary use of clinical data for research purposes.

\section{Data preprocessing}

Medication data related to VDES metabolites in the office and hospital pharmacy records were found for the following pharmaceutical compounds: cholecalciferol, calcifediol and calcitriol. Individuals are considered as treated with a specific metabolite if prescriptions were found within a period from $\mathrm{P}$ days ( $\mathrm{P}=15$ and 30 days) before the hospital admission until the discharge (or death). Otherwise they were considered as untreated. In parallel, individuals were considered treated with All Vitamin D Metabolites (ADM) in the case that one of the previous pharmaceutical compounds were prescribed. A total of 358 patients were treated with cholecalciferol, 193 with calcifediol, and 11 with calcitriol if a period of $\mathrm{P}=15$ days is 
considered, and 416, 210 and 15, respectively, if a $\mathrm{P}=30$ days period is considered. Calcitriol was excluded from the individual studies, due to the low $\mathrm{N}$, but was considered as ADM, totaling 562 and 641 for 15 and 30 days, respectively.

The main primary outcome used here was COVID-19 death events (certified death events during hospitalization). Following previous similar studies, the first 30 days of hospital stay were considered for survival calculations [27]. The time variable in the models correspond to the length (in days) of hospital stay.

\section{Propensity score matching}

To reduce the confounding effects of several conditions on the outcome a 1:1 ratio Propensity Score Matching (PSM) was applied to match treated and untreated patients without replacement in the survival analysis. Variables previously associated with COVID-19 mortality, such as: age, sex, pneumonia/flu vaccination status, hypertension, chronic obstructive pulmonary disease, diabetes, obesity, chronic pulmonary and digestive diseases, asthma, chronic heart diseases and cancer were included [28] (Table 2). The propensity scores have been estimated by means of a Generalized Additive Model with a logit as the link function while the matching, to ensure a similar distribution of all the covariates across treatment groups, has been done using the nearest neighbor matching modality [29]. To ensure a similar distribution of all the covariates across treatment groups (beyond considering only standardized means differences) the higher order moments of covariates were used as recently recommended [30]. Covariate balance in matched samples is checked by a $\mathrm{X}^{2}$ test to confirm that no biases against treated or untreated matched patients exist.

\section{Survival on the matched samples}

Kaplan-Meier estimate was used to infer the survival probability difference between treated and untreated patients. Survival curves for the different treatments are compared with a Log Rank test.

\section{Robust estimation of the treatment effect using the whole population}

Although PSM is a widely used technique because it leverages the use of parametric and non-parametric models to covariate-treatment-outcome unbalanced data, the consistency of any estimator derived from the propensity scores is limited by exchangeability assumptions between the treated and untreated samples, the covariate adjustment and model specification (among others) mainly due to the fact that the propensity score is computed with the same data as the modelling. Here, the hazard ratios for each of the treatments of interest have been computed by means of the closed-form estimator [31] using a weighted Cox model with inverse propensity weighting under the Average Treatment Effect on the Overall (ATE) and the Average Treatment Effect on the Treated (ATT) assumptions, the most used weighting 
approximations to estimate treatment effects [32]. Note that the ATE weights are stabilized by factoring the overall probability of being exposed to a given treatment into the equation [31].

Furthermore, an alternative estimation of the treatment effect has been obtained by means of bootstrapping ( $\mathrm{n}=10000$ iterations) a weighted Cox model with the propensity weights computed by means of a Binomial General Linear Model (GLM) which regress the treatment as a function of the covariates [33].

\section{Modeling survival along time}

For each time point the restricted mean survival time (RMST) of the treated versus the untreated for each treatment has been compared. The RMST is computed as the area under the survival curve up to the time point $(t)$ and, therefore, the comparison measures the difference and ratio of RMST between treated and untreated patients. The interpretation of the curve is straightforward, representing each time point $(t)$ the expected days (on average) that subjects from the treatment group live longer (or shorter) than untreated patients when patients are followed up to time $t$. Interestingly, the significance of the RMST comparison can be estimated (FDR corrected p-value) for each time point. Note that the dynamic estimated ratio of RMST is more prone to detect plateaus on the treatment effect over time [34], so both curves are complementary.

\section{Software}

For the matching analysis we have used the MatchIt [35] R package (version 4.1.0). The treatment effect models have been implemented with the hrIPW [36] R package (version 0.1.3). RMST computations have been performed with the survRM2 [37] R package (version 1.0.3). Survival curves and plots have been generated with the $\mathrm{R}$ survival [38] (version 3.2.7) and survminer [39] (version 0.4.8) packages, respectively.

\section{Results}

\section{Data processing}

A retrospective cohort of 16.401 patients, which include all Andalusian patients with COVID-19 diagnosis that were hospitalized between January and November 2020, was found in BPS and collected. Supplementary Figure 1 depicts the frequency of hospital admission of patients with COVID-19 diagnosis along this period. Patient data on medication and other relevant covariates (see Table 1) was downloaded from the BPS. 
medRxiv preprint doi: https://doi.org/10.1101/2021.04.27.21255937; this version posted April 29, 2021. The copyright holder for this preprint (which was not certified by peer review) is the author/funder, who has granted medRxiv a license to display the preprint in perpetuity.

It is made available under a CC-BY-NC-ND 4.0 International license .

\section{Vitamin D endocrine system metabolites and survival}

The effect of cholecalciferol, calcifediol or calcitriol treatment, both aggregated (ADM) and independently, 15 and 30 days before hospitalization, was studied with respect to the outcome death at 30 days. As described in methods, PSM was applied to the treated and untreated patients. This rendered a satisfactory covariate balance and no significant correlations between the covariates was observed in the samples paired by the PSM model (Table 3). Kaplan-Meier curves shows the survival of patients treated with ADM 15 days (Figure 1A) and 30 days (Figure 1B) before hospitalization, suggesting a significant association between ADM treatment and patient survival. Kaplan-Meier curves for specific cholecalciferol, calcifediol or calcitriol treatments (Supplementary Figure 2) supporting the same significant association between any of the individual treatments and patient survival. The comparison of specific treatments supports a significantly increased survival of patients treated with calcifediol than those treated with cholecalciferol (see Table 4), pointing to a stronger association of calcifediol with patient survival.

To study in more detail the protective effect of VDES treatment a Cox regression was used to estimate the degree of association between the treatments and death risk by means of the hazard ratios. Figure 2 summarizes the log hazard ratios with respect to the outcome death for the calcifediol and cholecalciferol treatments as well as the ADM treatments aggregated, in the two periods of administration considered (15 and 30 days). The three treatments demonstrated a significant association with increased patient survival. From Figure 2 it becomes apparent that calcifediol shows a clearly higher association with patient survival than cholecalciferol, although this last metabolite also shows a non-negligible and significant effect. Calcitriol was not included, given the small sample size (16 patients). Additional analysis with different assumptions and different methodologies, such as bootstrap) support the results obtained (Supplementary Figure 3).

Additionally, a more sophisticated analysis has been carried out to determine in detail the effect of each treatment along time (RMSTs). The RMST curve represents the expected survival days (on average) that subjects from the treatment group have with respect to untreated patients along time. Supplementary Figure 4 shows that calcifediol treatment shows a significantly better survival than untreated for all the 30 days interval studied. Cholecalciferol treatment shows better survival than untreated patients as well, although it is only statistically significant for a short period, and only in the case of prescription during the 15 days before admission.

\section{Discussion}


Andalusia, with 8.5 million inhabitants is the third largest region in Europe, having a population similar to Austria and being bigger than half of the countries of the European Union. Moreover, it has the largest population under a universal EHR. All the data recorded by the Andalusian Public Health System is stored in the BPS. This allowed an unprecedented regionwise cohort study of 16,401 patients, which corresponds to all the COVID-19 patients that were hospitalized between January and November 2020.

This large-scale RWE study clearly shows that pre-treatment for another indication with VDES metabolites significantly reduces the risk of death in patients hospitalized for COVD-19, This effect is stronger in patients taking calcifediol, but also occurs in patients taking cholecalciferol and most likely with calcitriol as well (although due to the small sample size its effect was not statistically significant). To our knowledge, this is the first study to investigate the effect of pre-admission treatment with VDES metabolites (cholecalciferol, calcifediol or calcitriol) on death in patients hospitalized for COVID. Moreover, due to the country-size scale of this observational study it is easy to mimic the randomization element of an RTC and properly compare treatment groups, given the number of individuals available to properly adjust for all baseline cofounders [40]. Actually, the use of propensity scores provides additional adjustment to control for confounding variables [41]. Here, as shown in Table 3, confounding effects between the compared groups due to the known variables associated to the outcomes considered can be ruled out.

The consistency of the results presented here strongly suggests that patients that had adjusted their serum levels of 25OHD for other health objectives presented a better response to COVID-19. Recently, numerous epidemiological and association studies have been published investigating the links between circulating levels of $25 \mathrm{OHD}$, and the incidence and severity of COVID-19 infections [6-13]. Initially, these were observational ecologic studies that described a higher incidence of COVID-19 infection and death in countries where vitamin D deficiency (or low sun exposure) was common [11, 42-44]. Thereafter, several studies evaluated the association between vitamin D status and risk or severity of SARS-CoV-2 infection [4-11]. These results suggest that improving serum 25OHD concentration may improve the prognosis of COVID-19 [11-13], as demonstrated by a pilot controlled trial that reported that administration of calcifediol versus no calcifediol reduced the need for ICU treatment in 76 hospitalized participants with COVID-19 who also received best available therapy [45, 46].

From a mechanistic perspective, there is good reason to postulate that the vitamin D endocrine system may have beneficial effects on different stages of COVID-19 infections such as the early viral infection (by innate antiviral effector mechanisms, including induction of antimicrobial peptides and autophagy) and the later hyperinflammatory phase of COVID-19 
medRxiv preprint doi: https://doi.org/10.1101/2021.04.27.21255937; this version posted April 29, 2021. The copyright holder for this preprint (which was not certified by peer review) is the author/funder, who has granted medRxiv a license to display the preprint in perpetuity. It is made available under a CC-BY-NC-ND 4.0 International license .

[47-49]. Moreover, activation of the vitamin D receptor (VDR) signaling pathway may have a critical modulatory role to host responses in acute respiratory distress syndrome $[1,48]$ by decreasing the cytokine/chemokine storm, producing a shift towards amplified adaptive Th2 immune responses, regulating the renin-angiotensin-bradykinin system (RAS), modulating neutrophil activity [50] and maintaining the integrity of the pulmonary epithelial barrier, stimulating epithelial repair [51-53] and decreasing the increased coagulability and prothrombotic tendency associated with severe COVID-19 [47, 48, 54, 55] Regulation of the renin-angiotensin-bradykinin system is of particular relevance in mitigating the progression of severe COVID-19, where over-activation of RAS is associated with a poor prognosis [56]. Moreover, the protective effect of drugs targeting the $V D R$ and the $G C$ (Vitamin D Binding Protein or $V D B P$ ) proteins of VDES has been suggested in a recent study on systematic drug repurposing for COVID-19 [16]. The ML study has demonstrated the relevance of drugs targeting $V D R$ and $G C(V D B P)$ proteins in the activity of COVID19-related signaling circuits (see Supplementary Table 1). These signaling circuits affect cellular processes involved in modulating the immune activity, decreasing the inflammatory response, but also in slowing down cellular energetics.

Thus, both observational evidence and mechanistic knowledge support a crucial role of the vitamin D endocrine system, especially calcifediol, in the response to severe outcomes of the COVID-19.

\section{Conclusions}

This study strongly suggests that calcifediol or cholecalciferol treatments established previously to hospitalization were associated with a better survival rate among patients hospitalized because of COVID-19, most likely through VDR stimulation. VDES metabolite treatment may represent an effective, accessible, safe, well-tolerated and cost-effective preventive therapeutic approach for COVID-19, which is dramatically increasing in incidence and for which few validated treatments currently exist. Further large prospective, preferably interventional, Randomized Controlled Trials are needed to confirm whether regular treatment or supplementation of older adults with calcifediol or vitamin D3 improves COVID-19 outcomes.

The results reported here support the establishment of public health policies that make it possible to maintain adequate levels of $25 \mathrm{OHD}$ for the synthesis of calcitriol to enable a better prognosis in patients affected by COVID-19. In the light of the results obtained, calcifediol preferably, or cholecalciferol with a lower effect, can adequately meet these objectives. In fact, calcifediol may have some advantages over native vitamin D3. Thus, the former has a more reliable intestinal absorption (close to $100 \%$ ) and can rapidly restore serum concentrations of 
medRxiv preprint doi: https://doi.org/10.1101/2021.04.27.21255937; this version posted April 29, 2021. The copyright holder for this preprint

$25 \mathrm{OHD}$ as it does not require hepatic 25 -hydroxylation. This is especially relevant in clinical situations whereby rapid restoration of serum 25OHD is desirable and $C Y P 2 R 1$ expression is compromised [57]. This cost-effective and widely available treatment could have positive implications for the management of COVID-19 worldwide, particularly in developing countries.

\section{Authors' contributions}

Carlos Loucera: Data curation, Formal Analysis, Investigation, Visualization; María Peña-Chilet: Formal Analysis; Marina Esteban-Medina: Formal Analysis; Dolores MuñoyerroMuñiz: Resources; Román Villegas: Resources; Jose Lopez-Miranda: Writing - review \& editing; Jesus Rodriguez-Baño: Writing - review \& editing; Isaac Túnez: Writing - review \& editing; Roger Bouillon: Writing - review \& editing; Joaquin Dopazo: Supervision, Project administration, Writing - original draft; Jose Manuel Quesada Gomez: Supervision, Writing original draft.

\section{Conflict of interest statements}

RB declares payment of honoraria for lectures by FAES (Spain), Abiogen (Italy) and Fresenius (Germany). JMQ declares small consulting fees and small lecture fees from Amgen and FASE Farma (Spain). The rest of authors declare that there are no conflicts of interest

\section{Role of funding source}

The funding sources have no role in this work.

\section{Ethics committee approval}

The Ethics Committee for the Coordination of Biomedical Research in Andalusia approved the study "Retrospective analysis of all COVID-19 patients in the entire Andalusian community and generation of a prognostic predictor that can be applied preventively in possible future outbreaks“ (29th September, 2020, Acta 09/20) and waived informed consent for the secondary use of clinical data for research purposes.

\section{Acknowledgements}

This work is supported by grants SAF2017-88908-R from the Spanish Ministry of Economy and Competitiveness, PT17/0009/0006, ACCI2018/29 from CIBERER-ISCIII; COV20/00788 from the Instituto de Salud Carlos III (ISCIII), co-funded with European Regional Development Funds (ERDF); grant G999088Q from the Fundación BBVA; grant H2020 Programme of the European Union grants Marie Curie Innovative Training Network "Machine Learning Frontiers in Precision Medicine" (MLFPM) (GA 813533); P18-RT-3471 from Consejería de Salud y Familias de la Junta de Andalucía; CB16/10/00245, CB16/10/00501 from CIBERFES-ISCIII; PI19/00033 from the ISCIII, co-funded with ERDF; COVID-011- 
medRxiv preprint doi: https://doi.org/10.1101/2021.04.27.21255937; this version posted April 29, 2021. The copyright holder for this preprint

(which was not certified by peer review) is the author/funder, who has granted medRxiv a license to display the preprint in perpetuity.

It is made available under a CC-BY-NC-ND 4.0 International license .

2020 from Consejería de Salud y Familia. The authors also acknowledge Junta de Andalucía for the postdoctoral contract of Carlos Loucera (PAIDI2020- DOC_00350) co-funded by the European Social Fund (FSE) 2014-2020.

\section{References}

1. Bouillon R, Marcocci C, Carmeliet G, Bikle D, White JH, Dawson-Hughes B, et al. Skeletal and extraskeletal actions of vitamin D: current evidence and outstanding questions. Endocrine reviews. 2019;40(4):1109-51.

2. Jiang $X, G e T$, Chen $\mathrm{C}-\mathrm{Y}$. The causal role of circulating vitamin $\mathrm{D}$ concentrations in human complex traits and diseases: a large-scale Mendelian randomization study. Scientific reports. 2021;11(1):1-10.

3. Martineau AR, Jolliffe DA, Hooper RL, Greenberg L, Aloia JF, Bergman P, et al. Vitamin $D$ supplementation to prevent acute respiratory tract infections: systematic review and metaanalysis of individual participant data. bmj. 2017;356.

4. Merzon E, Tworowski D, Gorohovski A, Vinker S, Golan Cohen A, Green I, et al. Low plasma $25(\mathrm{OH})$ vitamin D level is associated with increased risk of COVID-19 infection: an Israeli population-based study. The FEBS journal. 2020;287(17):3693-702.

5. Meltzer DO, Best TJ, Zhang H, Vokes T, Arora V, Solway J. Association of vitamin D status and other clinical characteristics with COVID-19 test results. JAMA network open. 2020;3(9):e2019722-e.

6. Hernández JL, Nan D, Fernandez-Ayala M, García-Unzueta M, Hernández-Hernández MA, López-Hoyos M, et al. Vitamin D status in hospitalized patients with SARS-CoV-2 infection. The Journal of clinical endocrinology and metabolism. 2020.

7. Kaufman HW, Niles JK, Kroll MH, Bi C, Holick MF. SARS-CoV-2 positivity rates associated with circulating 25-hydroxyvitamin D levels. PLoS One. 2020;15(9):e0239252.

8. Baktash V, Hosack T, Patel N, Shah S, Kandiah P, Van Den Abbeele K, et al. Vitamin D status and outcomes for hospitalised older patients with COVID-19. Postgraduate medical journal. 2020.

9. Faul J, Kerley C, Love B, O'Neill E, Cody C, Tormey W, et al. Vitamin D deficiency and ARDS after SARS-CoV-2 infection. 2020.

10. Radujkovic A, Hippchen T, Tiwari-Heckler S, Dreher S, Boxberger M, Merle U. Vitamin D deficiency and outcome of COVID-19 patients. Nutrients. 2020;12(9):2757.

11. Bassatne A, Basbous M, Chakhtoura M, El Zein O, Rahme M, Fuleihan GE-H. The link between COVID-19 and VItamin D (VIVID): a systematic review and meta-analysis. Metabolism. 2021:154753.

12. Liu N, Sun J, Wang X, Zhang T, Zhao M, Li H. Low vitamin D status is associated with coronavirus disease 2019 outcomes: A systematic review and meta-analysis. International Journal of Infectious Diseases. 2021.

13. Pereira M, Dantas Damascena A, Galvão Azevedo LM, de Almeida Oliveira T, da Mota Santana J. Vitamin D deficiency aggravates COVID-19: systematic review and meta-analysis. Critical reviews in food science and nutrition. 2020:1-9.

14. NICE guideline COVID-19 rapid guideline:vitamin D 2020 [cited 2021 03/02/]. Available from: http://www.nice.org.uk/guidance/ng187.

15. H.Res.116 - Recognizing the benefits of vitamin $D$ intake for preventing respiratory infection and COVID-19 complications 2021 [cited 2021 03/02/]. Available from: https://www.congress.gov/bill/117th-congress/house-resolution/116/text?r=3\&s=1. 16. Loucera C, Esteban-Medina M, Rian K, Falco MM, Dopazo J, Peña-Chilet M. Drug repurposing for COVID-19 using machine learning and mechanistic models of signal 
medRxiv preprint doi: https://doi.org/10.1101/2021.04.27.21255937; this version posted April 29, 2021. The copyright holder for this preprint

(which was not certified by peer review) is the author/funder, who has granted medRxiv a license to display the preprint in perpetuity.

It is made available under a CC-BY-NC-ND 4.0 International license .

transduction circuits related to SARS-CoV-2 infection. Signal Transduction and Targeted Therapy. 2020;5(1):290. doi: 10.1038/s41392-020-00417-y.

17. Rian K, Esteban-Medina M, Hidalgo MR, Çubuk C, Falco MM, Loucera C, et al. Mechanistic modeling of the SARS-CoV-2 disease map. BioData Min. 2021;14(1):5. Epub 2021/01/23. doi: 10.1186/s13040-021-00234-1. PubMed PMID: 33478554; PubMed Central PMCID: PMCPMC7817765.

18. Ostaszewski M, Mazein A, Gillespie ME, Kuperstein I, Niarakis A, Hermjakob H, et al. COVID-19 Disease Map, building a computational repository of SARS-CoV-2 virus-host interaction mechanisms. Sci Data. 2020;7(1).

19. Bothwell LE, Podolsky SH. The emergence of the randomized, controlled trial. N Engl J Med. 2016;375(6):501-4.

20. Corrigan-Curay J, Sacks L, Woodcock J. Real-World Evidence and Real-World Data for Evaluating Drug Safety and Effectiveness. JAMA : the journal of the American Medical Association. 2018;320(9):867-8. doi: 10.1001/jama.2018.10136.

21. US Food and Drug Administration. Use of real-world evidence to support regulatory decision-making for medical devices: guidance for industry and Food and Drug Administration staff 2017 [cited 2021 28/02/]. Available from:

https://www.fda.gov/downloads/medicaldevices/deviceregulationandguidance/guidancedocu ments/ucm513027.pdf.

22. Sherman RE, Anderson SA, Dal Pan GJ, Gray GW, Gross T, Hunter NL, et al. Real-world evidence-what is it and what can it tell us. N Engl J Med. 2016;375(23):2293-7.

23. Hannan EL. Randomized clinical trials and observational studies: guidelines for assessing respective strengths and limitations. JACC: Cardiovascular Interventions. 2008;1(3):211-7.

24. Cowie MR, Blomster JI, Curtis LH, Duclaux S, Ford I, Fritz F, et al. Electronic health records to facilitate clinical research. Clinical Research in Cardiology. 2017;106(1):1-9.

25. Muñoyerro-Muñiz D, Goicoechea-Salazar J, García-León F, Laguna-Tellez A, LarrochaMata D, Cardero-Rivas M. Health record linkage: Andalusian health population database. Gaceta Sanitaria. 2019;34(2):105-13.

26. García-León F, Villegas-Portero R, Goicoechea-Salazar J, Muñoyerro-Muñiz D, Dopazo J. Impact assessment on data protection in research projects. Gaceta sanitaria. 2020.

27. Sterne JA, Murthy S, Diaz JV, Slutsky AS, Villar J, Angus DC, et al. Association between administration of systemic corticosteroids and mortality among critically ill patients with COVID-19: a meta-analysis. JAMA : the journal of the American Medical Association. 2020;324(13):1330-41.

28. Gutiérrez-Gutiérrez B, del Toro MD, Borobia AM, Carcas A, Jarrín I, Yllescas M, et al. Identification and validation of clinical phenotypes with prognostic implications in patients admitted to hospital with COVID-19: a multicentre cohort study. The Lancet infectious diseases. 2021. doi: https://doi.org/10.1016/S1473-3099(21)00019-0.

29. Zakrison T, Austin P, McCredie V. A systematic review of propensity score methods in the acute care surgery literature: avoiding the pitfalls and proposing a set of reporting guidelines. European Journal of Trauma and Emergency Surgery. 2018;44(3):385-95.

30. Ho DE, Imai K, King G, Stuart EA. Matching as nonparametric preprocessing for reducing model dependence in parametric causal inference. Political analysis. 2007;15(3):199236.

31. Hajage D, Chauvet G, Belin L, Lafourcade A, Tubach F, De Rycke Y. Closed-form variance estimator for weighted propensity score estimators with survival outcome. Biometrical Journal. 2018;60(6):1151-63.

32. Imbens GW. Nonparametric estimation of average treatment effects under exogeneity: A review. Review of Economics and statistics. 2004;86(1):4-29.

33. Austin PC. Variance estimation when using inverse probability of treatment weighting (IPTW) with survival analysis. Statistics in medicine. 2016;35(30):5642-55. 
medRxiv preprint doi: https://doi.org/10.1101/2021.04.27.21255937; this version posted April 29, 2021. The copyright holder for this preprint

(which was not certified by peer review) is the author/funder, who has granted medRxiv a license to display the preprint in perpetuity.

It is made available under a CC-BY-NC-ND 4.0 International license .

34. Liao JJ, Liu GF, Wu W-C. Dynamic RMST curves for survival analysis in clinical trials. BMC Medical Research Methodology. 2020;20(1):1-10.

35. Stuart EA, King G, Imai K, Ho D. Matchlt: nonparametric preprocessing for parametric causal inference. Journal of statistical software. 2011.

36. Hajage D. hrlPW: Hazard Ratio Estimation using Cox Model Weighted by the Estimated Propensity Score 2020 [cited 2021 28/02/]. Available from: https://CRAN.Rproject.org/package=hrlPW.

37. Uno H, Tian L, Horiguchi M, Cronin A, Battioui C, Bell J. survRM2: Comparing Restricted Mean Survival Time 2020 [cited 2021 28/02/]. Available from: https://CRAN.R-

project.org/package=survRM2.

38. Therneau T. A Package for Survival Analysis in R 2020 [cited 2021 28/02/]. Available from: https://CRAN.R-project.org/package=survival.

39. Kassambara A, Kosinski M, Biecek P, Fabian S. Package 'survminer'. Drawing Survival Curves using 'ggplot2' (R package version 03 1). 2017.

40. Carrigan G, Whipple S, Capra WB, Taylor MD, Brown JS, Lu M, et al. Using electronic health records to derive control arms for early phase single-arm lung cancer trials: proof-of-concept in randomized controlled trials. Clinical Pharmacology \& Therapeutics. 2020;107(2):369-77.

41. Ramagopalan SV, Simpson A, Sammon C. Can real-world data really replace randomised clinical trials? BMC medicine. 2020;18(1):1-2.

42. Rhodes JM, Subramanian S, Laird E, Kenny RA. low population mortality from COVID-19 in countries south of latitude 35 degrees North supports vitamin $D$ as a factor determining severity. Wiley Online Library; 2020.

43. Ilie PC, Stefanescu S, Smith L. The role of vitamin D in the prevention of coronavirus disease 2019 infection and mortality. Aging clinical and experimental research.

2020;32(7):1195-8.

44. Marik PE, Kory P, Varon J. Does vitamin D status impact mortality from SARS-CoV-2 infection? Medicine in drug discovery. 2020;6:100041.

45. Castillo ME, Costa LME, Barrios JMV, Díaz JFA, Miranda JL, Bouillon R, et al. Effect of calcifediol treatment and best available therapy versus best available therapy on intensive care unit admission and mortality among patients hospitalized for COVID-19: A pilot randomized clinical study. The Journal of steroid biochemistry and molecular biology. 2020;203:105751. 46. Jungreis I, Kellis M. Mathematical analysis of Córdoba calcifediol trial suggests strong role for Vitamin D in reducing ICU admissions of hospitalized COVID-19 patients. medRxiv. 2020.

47. Bilezikian JP, Bikle D, Hewison M, Lazaretti-Castro M, Formenti AM, Gupta A, et al. Mechanisms in endocrinology: vitamin $D$ and COVID-19. European journal of endocrinology. 2020;183(5):R133-R47.

48. Quesada-Gomez JM, Entrenas-Castillo M, Bouillon R. Vitamin D receptor stimulation to reduce acute respiratory distress syndrome (ARDS) in patients with coronavirus SARS-CoV-2 infections: Revised Ms SBMB 2020_166. The Journal of steroid biochemistry and molecular biology. 2020;202:105719.

49. Grant WB, Lahore H, McDonnell SL, Baggerly CA, French CB, Aliano JL, et al. Evidence that vitamin $D$ supplementation could reduce risk of influenza and COVID-19 infections and deaths. Nutrients. 2020;12(4):988.

50. Takano Y, Mitsuhashi H, Ueno K. 1 $\alpha, 25$-Dihydroxyvitamin D3 inhibits neutrophil recruitment in hamster model of acute lung injury. Steroids. 2011;76(12):1305-9.

51. Zheng S, Yang J, Hu X, Li M, Wang Q, Dancer RC, et al. Vitamin D attenuates lung injury via stimulating epithelial repair, reducing epithelial cell apoptosis and inhibits TGF- $\beta$ induced epithelial to mesenchymal transition. Biochemical pharmacology. 2020;177:113955. 
medRxiv preprint doi: https://doi.org/10.1101/2021.04.27.21255937; this version posted April 29, 2021. The copyright holder for this preprint

(which was not certified by peer review) is the author/funder, who has granted medRxiv a license to display the preprint in perpetuity.

It is made available under a CC-BY-NC-ND 4.0 International license.

52. Kong J, Zhu X, Shi Y, Liu T, Chen Y, Bhan I, et al. VDR attenuates acute lung injury by blocking Ang-2-Tie-2 pathway and renin-angiotensin system. Molecular endocrinology. 2013;27(12):2116-25.

53. $\quad$ Shi YY, Liu TJ, Fu JH, Xu W, Wu LL, Hou AN, et al. Vitamin D/VDR signaling attenuates lipopolysaccharide?induced acute lung injury by maintaining the integrity of the pulmonary epithelial barrier. Molecular medicine reports. 2016;13(2):1186-94.

54. Martinez-Moreno JM, Herencia C, Oca AMd, Muñoz-Castañeda JR, Rodríguez-Ortiz ME, Díaz-Tocados JM, et al. Vitamin D modulates tissue factor and protease-activated receptor 2 expression in vascular smooth muscle cells. The FASEB Journal. 2016;30(3):1367-76.

55. Blondon M, Biver E, Braillard O, Righini M, Fontana P, Casini A. Thrombin generation and fibrin clot structure after vitamin $D$ supplementation. Endocrine connections.

2019;8(11):1447-54.

56. Xu J, Yang J, Chen J, Luo Q, Zhang Q, Zhang H. Vitamin D alleviates

lipopolysaccharide? ?induced acute lung injury via regulation of the renin?angiotensin system. Molecular medicine reports. 2017;16(5):7432-8.

57. Quesada-Gomez J, Bouillon R. Is calcifediol better than cholecalciferol for vitamin D supplementation? Osteoporosis International. 2018;29(8):1697-711. 
Table 1. Data imported from BPS for each patient

\begin{tabular}{|l|l|}
\hline Code & Meaning \\
\hline FECNAC & Birth date \\
\hline FECDEF & Death date \\
\hline SEXO & Gender \\
\hline FEC_INGRESO & Hospital admission date \\
\hline FEC_ALTA & Discharge date \\
\hline MOTIVO_ALTA & $\begin{array}{l}\text { Reason for the discharge: (recovery/death/admission in } \\
\text { another hospital/voluntary discharge/retirement } \\
\text { home/unspecified) }\end{array}$ \\
\hline DIAS_UCI & Days in ICU \\
\hline COD_PATOLOGIA_CRONICA & Hospital codes for chronic conditions \\
\hline COD_FEC_INI_PATOLOGIA & Date of condition diagnosis \\
\hline COD_CIE_NORMALIZADO & A mixture of ICD9 and ICD10 codes for diseases \\
\hline DESC_CIE_NORMALIZADO & Description of the ICD \\
\hline FECINI_DIAG & Diagnosis date \\
\hline FECFIN_DIAG & End of the diagnosed condition \\
\hline FUENTE_DIAG & Source of the diagnosis (hospital, emergency, etc.) \\
\hline IND_CRONICO_HCUP & Is a chronic disease? (yes/no) \\
\hline Test COVID: FECHA & Test COVID date \\
\hline Test COVID: TYPE & PCR / antigens \\
\hline Test COVID: RESULTADO_TEST & Result of the test (positive/negative) \\
\hline $\begin{array}{l}\text { Pharmacy (Hospital and external): } \\
\text { DESCRIPCION }\end{array}$ & $\begin{array}{l}\text { List of drugs used in hospital or purchased in the } \\
\text { pharmacies }\end{array}$ \\
\hline $\begin{array}{l}\text { Pharmacy (Hospital and external): } \\
\text { FECHA }\end{array}$ & Dispensing date \\
\hline VACUNA & List of vaccines \\
\hline VACUNAFECHA & Vaccination dates \\
\hline 1 Only positive were considered in this study \\
\hline
\end{tabular}


medRxiv preprint doi: https://doi.org/10.1101/2021.04.27.21255937; this version posted April 29, 2021. The copyright holder for this preprint (which was not certified by peer review) is the author/funder, who has granted medRxiv a license to display the preprint in perpetuity.

It is made available under a CC-BY-NC-ND 4.0 International license .

Table 2. Variables previously associated to COVID-19 prognosis and symptoms observed in the whole set of patients. Columns survival and death contain the absolute number of individuals with the specific covariate, and in parentheses the percentage, that survive and die, respectively. $\mathrm{A} \mathrm{X}^{2}$ test is carried out to check for direct associations (with no covariate correction) with death. The difference of percentages accounts for the effect: e.g. asthma protects and cancer increases the risk. The p-value column accounts for the significance. All the values agree with previous reports.

\begin{tabular}{|c|c|c|c|c|}
\hline Days & Covariate & Survival & Death & p-value \\
\hline 30 & Total N & 13350 & 3019 & \\
\hline 30 & $\mathrm{~N}$ cross-treated & 27 & 1 & \\
\hline 30 & Asthma & $1642(12.3)$ & $291(9.6)$ & $<0.001$ \\
\hline 30 & Cancer & $1513(11.3)$ & $630(20.9)$ & $<0.001$ \\
\hline 30 & Chronic heart diseases & $3318(24.9)$ & $1397(46.3)$ & $<0.001$ \\
\hline 30 & Diabetes & $3788(28.4)$ & $1319(43.7)$ & $<0.001$ \\
\hline 30 & Hypertension & $7537(56.5)$ & $2306(76.4)$ & $<0.001$ \\
\hline 30 & Obesity & $2320(17.4)$ & $517(17.1)$ & 0.760 \\
\hline 30 & Chronic pulmonary diseases & $1750(13.1)$ & $778(25.8)$ & $<0.001$ \\
\hline 30 & Flu vaccine & $5654(42.4)$ & $2003(66.3)$ & $<0.001$ \\
\hline 30 & Pneumococcal vaccine & $3481(26.1)$ & $1241(41.1)$ & $<0.001$ \\
\hline 30 & Dementia & $990(7.4)$ & $588(19.5)$ & $<0.001$ \\
\hline 30 & Sex (Female) & $6203(46.5)$ & $1241(41.1)$ & $<0.001$ \\
\hline 30 & Age_bin & & & $<0.001$ \\
\hline 30 & $(-0.001,41.0]$ & $1671(12.5)$ & $34(1.1)$ & \\
\hline 30 & $(41.0,68.0]$ & $6094(45.6)$ & $505(16.7)$ & \\
\hline 30 & $(68.0,105.0]$ & $5585(41.8)$ & $2480(82.1)$ & \\
\hline 15 & Total N & 13354 & 3020 & \\
\hline 15 & $\mathrm{~N}$ cross treated & 23 & 0 & \\
\hline 15 & Asthma & $1645(12.3)$ & $291(9.6)$ & $<0.001$ \\
\hline 15 & Cancer & $1513(11.3)$ & $630(20.9)$ & $<0.001$ \\
\hline 15 & Chronic heart diseases & $3319(24.9)$ & $1398(46.3)$ & $<0.001$ \\
\hline 15 & Diabetes & $3790(28.4)$ & $1320(43.7)$ & $<0.001$ \\
\hline 15 & Hypertension & $7541(56.5)$ & $2307(76.4)$ & $<0.001$ \\
\hline 15 & Obesity & $2320(17.4)$ & $517(17.1)$ & 0.759 \\
\hline 15 & Chronic pulmonary diseases & $1752(13.1)$ & $778(25.8)$ & $<0.001$ \\
\hline 15 & Flu vaccine & $5658(42.4)$ & $2004(66.4)$ & $<0.001$ \\
\hline 15 & Pneumococcal vaccine & $3482(26.1)$ & $1241(41.1)$ & $<0.001$ \\
\hline 15 & Dementia & $990(7.4)$ & $589(19.5)$ & $<0.001$ \\
\hline 15 & Sex (Female) & $6207(46.5)$ & $1242(41.1)$ & $<0.001$ \\
\hline 15 & Age_bin & & & $<0.001$ \\
\hline 15 & $(-0.001,41.0]$ & $1671(12.5)$ & $34(1.1)$ & \\
\hline 15 & $(41.0,68.0]$ & $6096(45.6)$ & 505 (16.7) & \\
\hline 15 & $(68.0,105.0]$ & $5587(41.8)$ & $2481(82.2)$ & \\
\hline
\end{tabular}


medRxiv preprint doi: https://doi.org/10.1101/2021.04.27.21255937; this version posted April 29, 2021. The copyright holder for this preprint (which was not certified by peer review) is the author/funder, who has granted medRxiv a license to display the preprint in perpetuity.

It is made available under a CC-BY-NC-ND 4.0 International license .

Table 3. Matched covariates across treated and untreated patients. A $X^{2}$ test (column p-value) systematically non-significant demonstrates that the values are equilibrated between both groups.

\begin{tabular}{|c|c|c|c|c|}
\hline Days & Covariate & ADM Treated & ADM Untreated & p-value \\
\hline 30 & Total N & 641 & 641 & \\
\hline 30 & Asthma & $83(12.9)$ & $63(9.8)$ & 0.095 \\
\hline 30 & Cancer & $105(16.4)$ & $88(13.7)$ & 0.211 \\
\hline 30 & Chronic heart diseases & $220(34.3)$ & $226(35.3)$ & 0.769 \\
\hline 30 & Diabetes & $200(31.2)$ & $198(30.9)$ & 0.952 \\
\hline 30 & Hypertension & $412(64.3)$ & $417(65.1)$ & 0.815 \\
\hline 30 & Obesity & $104(16.2)$ & $104(16.2)$ & 1.000 \\
\hline 30 & Chronic pulmonary diseases & $108(16.8)$ & $93(14.5)$ & 0.282 \\
\hline 30 & Flu vaccine & $353(55.1)$ & $356(55.5)$ & 0.911 \\
\hline 30 & Pneumococcal vaccine & $241(37.6)$ & $249(38.8)$ & 0.687 \\
\hline 30 & Dementia & $50(7.8)$ & $47(7.3)$ & 0.833 \\
\hline 30 & Sex (Female) & $398(62.1)$ & 397 (61.9) & 1.000 \\
\hline 30 & Age_bin & & & 0.321 \\
\hline 30 & $(-0.001,41.0]$ & $41(6.4)$ & $54(8.4)$ & \\
\hline 30 & $(41.0,68.0]$ & $239(37.3)$ & $224(34.9)$ & \\
\hline 30 & $(68.0,105.0]$ & $361(56.3)$ & $363(56.6)$ & \\
\hline 15 & Total N & 562 & 562 & \\
\hline 15 & Asthma & $76(13.5)$ & $65(11.6)$ & 0.368 \\
\hline 15 & Cancer & $90(16.0)$ & $75(13.3)$ & 0.238 \\
\hline 15 & Chronic heart diseases & $181(32.2)$ & $181(32.2)$ & 1.000 \\
\hline 15 & Diabetes & $171(30.4)$ & $165(29.4)$ & 0.745 \\
\hline 15 & Hypertension & 359 (63.9) & $366(65.1)$ & 0.708 \\
\hline 15 & Obesity & $85(15.1)$ & $75(13.3)$ & 0.442 \\
\hline 15 & Chronic pulmonary diseases & $92(16.4)$ & $75(13.3)$ & 0.180 \\
\hline 15 & Flu vaccine & $299(53.2)$ & $306(54.4)$ & 0.720 \\
\hline 15 & Pneumococcal vaccine & $191(34.0)$ & $194(34.5)$ & 0.900 \\
\hline 15 & Dementia & $43(7.7)$ & $38(6.8)$ & 0.645 \\
\hline 15 & Sex (Female) & $350(62.3)$ & $347(61.7)$ & 0.902 \\
\hline 15 & Age_bin & & & 0.764 \\
\hline 15 & $(-0.001,41.0]$ & $37(6.6)$ & $42(7.5)$ & \\
\hline 15 & $(41.0,68.0]$ & $220(39.1)$ & $225(40.0)$ & \\
\hline 15 & $(68.0,105.0]$ & $305(54.3)$ & $295(52.5)$ & \\
\hline
\end{tabular}


Table 4. Comparison between the survival curves by the Log Rank test with the corresponding p-values both unadjusted and FDR-adjusted.

\begin{tabular}{|l|l|l|l|l|l|l|l|}
\hline Days & Treatment & $\begin{array}{l}\text { Calcifediol } \\
\text { (FDR-adjusted) }\end{array}$ & $\begin{array}{l}\text { Cholecalciferol } \\
\text { (FDR-adjusted) }\end{array}$ & $\begin{array}{l}\text { Calcitriol } \\
\text { (FDR-adjusted) }\end{array}$ & $\begin{array}{l}\text { Calcifediol } \\
\text { (unadjusted) }\end{array}$ & $\begin{array}{l}\text { Cholecalciferol } \\
\text { (unadjusted) }\end{array}$ & $\begin{array}{l}\text { Calcitriol } \\
\text { (unadjusted) }\end{array}$ \\
\hline 30 & Cholecalciferol & $0,0270^{*}$ & - & - & $0,0090^{* *}$ & - & - \\
\hline 30 & Calcitriol & 0,7253 & 0,8488 & - & 0,4835 & 0,8488 & - \\
\hline 30 & Untreated & $0,0030^{* *}$ & 0,4320 & 0,8488 & $0,0005^{* *}$ & 0,2160 & 0,8211 \\
\hline 15 & Cholecalciferol & 0,1299 & - & - & 0,0649 & - & - \\
\hline 15 & Calcitriol & 0,8080 & 0,8268 & - & 0,6733 & 0,8268 & - \\
\hline 15 & Untreated & $0,0074^{* *}$ & 0,1299 & 0,6511 & $0,0012^{* *}$ & 0,0562 & 0,4341 \\
\hline
\end{tabular}

${ }^{*}$ Test significant at $\alpha<0.05 ; * *$ test significant at $\alpha<0.01$; 
Prescription up to 30 days before admission

Strata $+\mathrm{ADM}=0+\mathrm{ADM}=1$

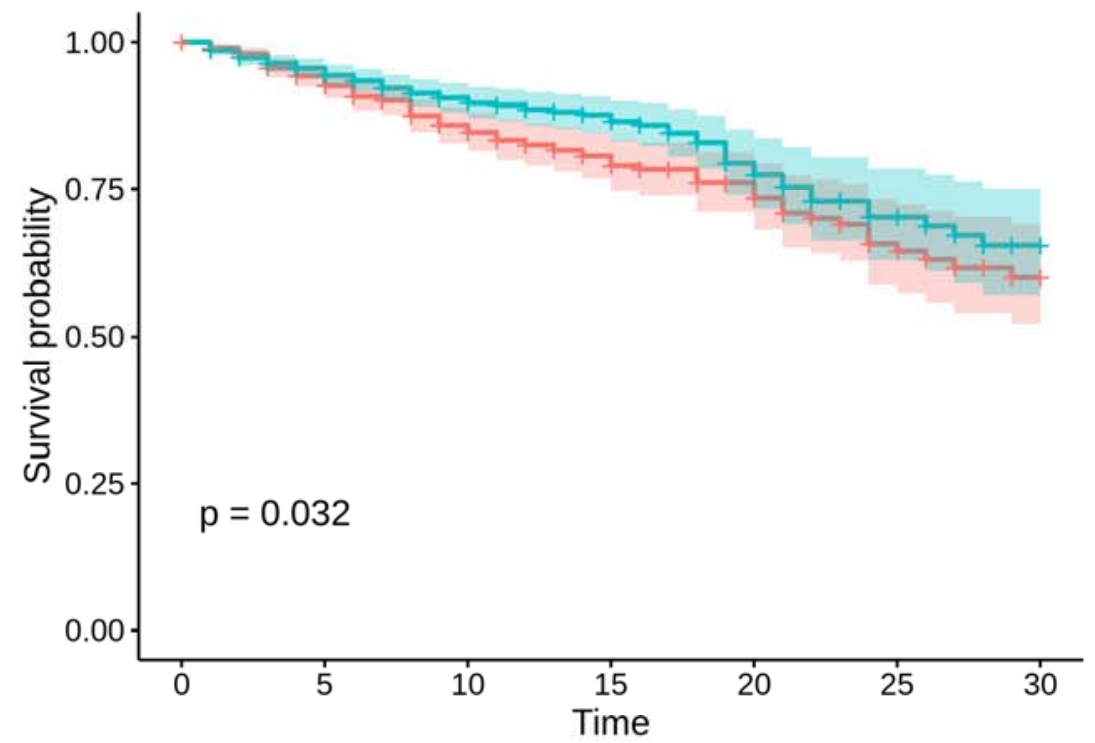

Number at risk (event Death)

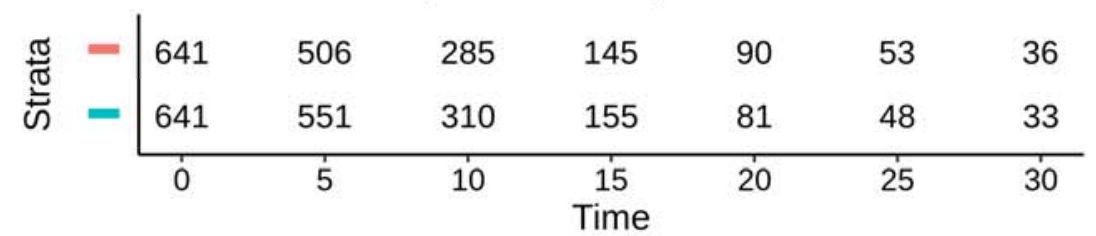

Prescription up to 15 days before admission

Strata $+\mathrm{ADM}=0+\mathrm{ADM}=1$

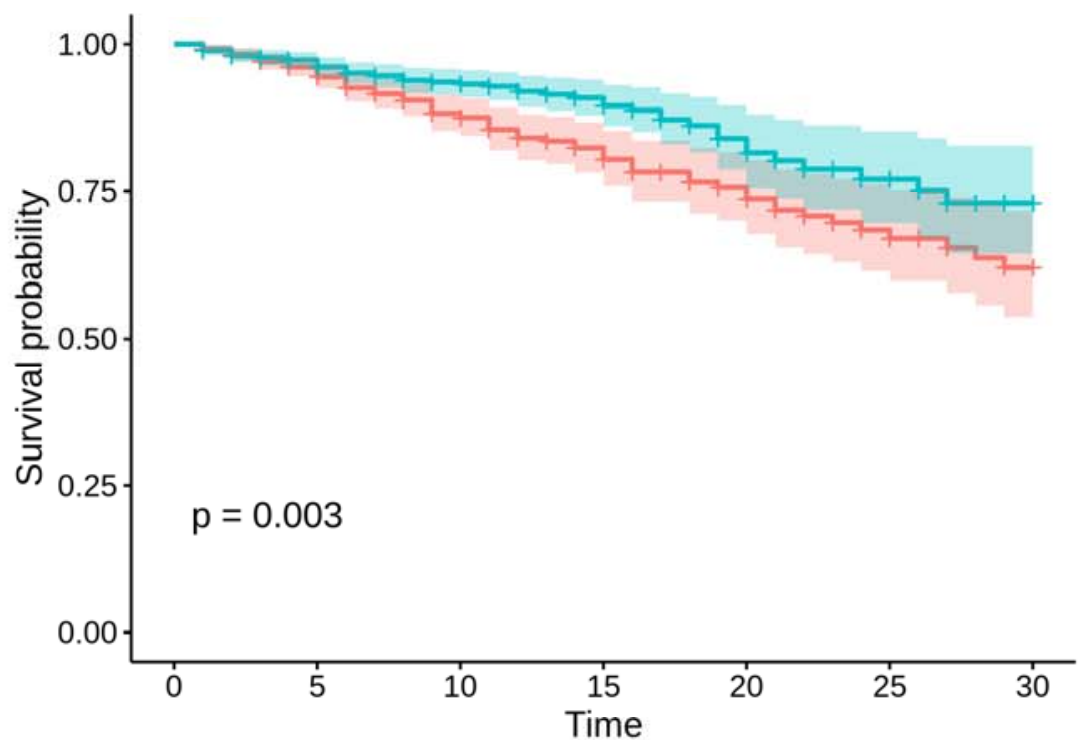

Number at risk (event Death)

\begin{tabular}{|c|c|c|c|c|c|c|c|}
\hline \multirow{3}{*}{$\frac{\widetilde{\pi}}{\stackrel{\frac{\pi}{*}}{\omega}}=$} & 562 & 457 & 248 & 127 & 80 & 48 & 35 \\
\hline & 562 & 492 & 281 & 136 & 69 & 41 & 27 \\
\hline & 0 & 5 & 10 & $\begin{array}{c}15 \\
\text { Time }\end{array}$ & 20 & 25 & 30 \\
\hline
\end{tabular}

Figure 1. Kaplan-Meier curves of patients treated with ADM A) 15 days and B) 30 days before hospitalization for death outcome. 


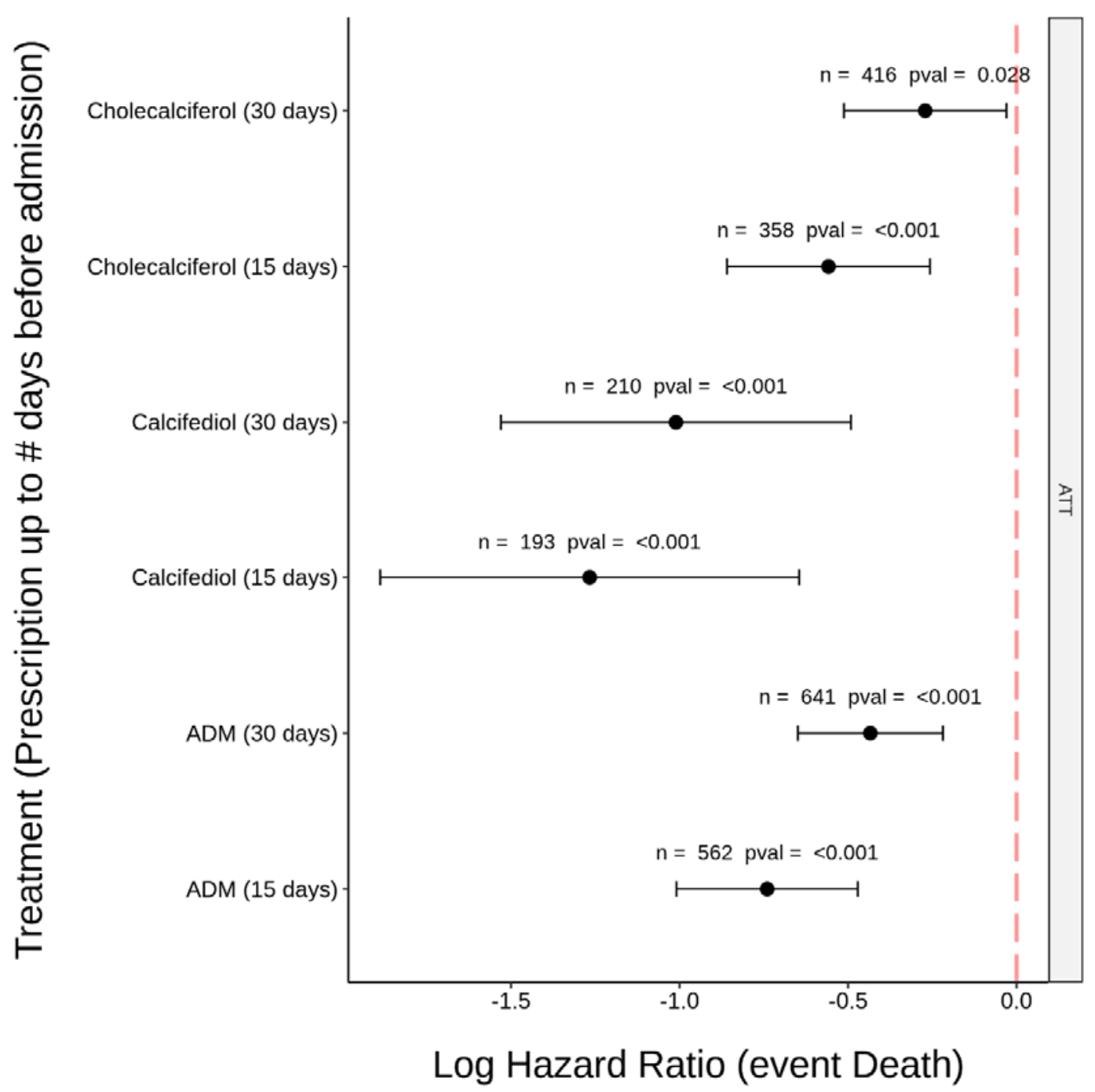

Figure 2. Log hazard ratios with respect to the outcome death under ATT assumption for the cholecalciferol, calcifediol and ADM treatments in the two periods considered (15 and 30 days before hospitalization). In all the cases a significant protective effect is observed: confidence intervals do not cross the 0 line $(\alpha=0.05)$ 